\title{
Characteristics of Subjects With Undiagnosed COPD Based on Post-Bronchodilator Spirometry Data
}

\author{
Stine Hangaard, Thomas Kronborg, and Ole K Hejlesen
}

\begin{abstract}
BACKGROUND: COPD is largely underdiagnosed. Patients with undiagnosed COPD need to be diagnosed to ensure early treatment institution. It is therefore relevant to obtain a more profound understanding of the characteristics of patients with undiagnosed COPD to improve COPD case finding. This study aimed to explore the characteristics of subjects with undiagnosed COPD from the United States National Health and Nutrition Examination Survey (NHANES) dataset (20072012) based on post-bronchodilator spirometry. METHODS: A multitude of statistical tests were performed to explore the potential characteristics of subjects with undiagnosed COPD. A total of 1,098 subjects with a post-bronchodilator $\mathrm{FEV}_{1} / \mathrm{FVC}<0.7$ or lower limit of normal (LLN) were included in the final sample. RESULTS: Undiagnosed subjects experienced less phlegm $(P<.001)$, wheezing $(P<.001)$, and chest pain $(P<.001)$ than subjects diagnosed with COPD. They were characterized by less shortness of breath $(P<.001)$, fewer work/school days lost to wheezing $(P<.001)$, less sleep disturbance $(P<.001)$, and less difficulty socializing $(P<.001)$. The undiagnosed subjects felt less depressed $(P<.001)$. Additionally, they were less likely to have asthma $(P<.001)$. The annual household income was higher among the undiagnosed subjects $(P<.001)$, and they were also characterized by higher $\mathrm{FEV}_{1}(P<.001)$, and FVC $(P<.001)$. CONCLUSIONS: Subjects with undiagnosed COPD were characterized by fewer symptoms and had better lung function than their diagnosed counterparts. Key words: obstructive lung disease; COPD; underdiagnosis; diagnosis; spirometry; case finding. [Respir Care 2019;64(1):63-70. ( 2019 Daedalus Enterprises]
\end{abstract}

\section{Introduction}

COPD is a chronic lung disease characterized by persistent air flow limitation due to a combination of small airways disease and parenchymal destruction. The symptoms of COPD include dyspnea, chronic cough, and increased production of sputum, among others. ${ }^{1,2}$ COPD is a leading cause of morbidity and mortality, ${ }^{2,3}$ and it is estimated to affect $210-600$ million people worldwide. ${ }^{3}$ The extent of COPD-related challenges is not completely clear

\footnotetext{
Ms Hangaard, Mr Kronborg, and Dr Hejlsen are affiliated with the Department of Health Science and Technology, Medical Informatics Group, Aalborg University, Aalborg, Denmark.

The authors report no conflicts of interest.

Correspondence: Stine Hangaard, Fredrik Bajers Vej 7C, 9220 Aalbog $\varnothing$, Denmark. E-mail: svh@hst.aau.dk.
}

DOI: $10.4187 /$ respcare.06296 due to a high degree of underdiagnosis and the lack of prevalence and incidence data from various countries. ${ }^{1,3}$

Currently, it is recommended that a diagnosis of COPD be considered in all patients with dyspnea, chronic cough, or production of sputum who have a history of exposure to COPD risk factors such as cigarette smoke or environmental pollutants. For the diagnosis of COPD, spirometry with an $\mathrm{FEV}_{1} / \mathrm{FVC}<0.7$ is necessary according to the definition from the Global Initiative for Chronic Lung Disease (GOLD). The American Thoracic Society/European Respiratory Society (ATS/ERS) recommends defining obstruction by an $\mathrm{FEV}_{1} / \mathrm{FVC}$ below the statistically defined lower fifth percentile of predicted normal values (ie, lower limit of normal, [LLN]). ${ }^{1}$ Moreover, the assessment of COPD should include assessment of symptoms, exacerbation risk, and comorbidities. ${ }^{2}$ However, even though the guidelines for COPD diagnosis are quite clear, ${ }^{2,4}$ COPD remains frequently underdiagnosed and misdiagnosed. . $^{3,5,6}$

Early identification of COPD patients is warranted to prevent disease progression, reduce exacerbations, ${ }^{2,3,7}$ and reduce health care costs. ${ }^{7}$ Therefore, it is of utmost rele- 


\section{Characteristics of Subjects With Undiagnosed COPD}

vance to recognize the characteristics of patients with undiagnosed COPD to optimize the chances of identifying and diagnosing these patients. Previous studies have explored the characteristics of patients with undiagnosed COPD, but they have not always been based on postbronchodilator spirometry. ${ }^{8,9}$ For instance, a study by Martinez et $\mathrm{al}^{8}$ explored factors associated with undiagnosed obstructive lung disease based on the National Health and Nutrition Examination Survey (NHANES) dataset focusing on pre-bronchodilator spirometry.

The aim of this study was to explore the characteristics of subjects with undiagnosed COPD from the NHANES dataset (2007-2012). Specifically, drawing on post-bronchodilator spirometry data, our objectives were to confirm or dismiss the relevance of previously identified characteristics and to add information on the unrecognized characteristics of subjects with undiagnosed COPD.

\section{Methods}

\section{Data}

NHANES provides publically available information regarding the health and nutritional status of the United States population, which includes demographic, nutritional, medical, and behavioral data obtained from examinations and interviews. ${ }^{10,11}$ Our study used the NHANES data set from 2007 to $2012(N=30,442$ subjects $)$; spirometry data were available for 23,433 subjects, of whom 21,869 had a postbronchodilator $\mathrm{FEV}_{1} / \mathrm{FVC} \geq 0.7$ or LLN and were therefore excluded from the final sample because they did not have spirometry-based obstruction. A total of 1,564 subjects had a post-bronchodilator $\mathrm{FEV}_{1} / \mathrm{FVC}<0.7$ or LLN. However, 466 of these subjects were excluded due to lack of response to questions regarding an existing diagnosis of COPD; thus, the final sample included 1,098 subjects with spirometry-based obstruction defined as $\mathrm{FEV}_{1} / \mathrm{FVC}<0.7$ or LLN. Of the final sample, 93 subjects had a previous diagnosis of COPD, whereas 1,005 subjects had no previous diagnosis of COPD (Fig. 1). However, not all subjects responded to all questions, and the sample size fluctuated throughout the analysis. The baseline characteristics of the subjects included in the study are presented in Table 1.

Due to a lack of supplemental diagnostic data, diagnosed COPD was defined solely based on spirometry as $\mathrm{FEV}_{1} / \mathrm{FVC}<0.7$ or LLN and a positive response to a minimum of one of the following questions: (1) Have you ever been told by a doctor or other health care professional that you have chronic bronchitis? (2) Have you ever been told by a doctor or other health care professional that you have emphysema? Undiagnosed COPD was defined as $\mathrm{FEV}_{1} / \mathrm{FVC}<0.7$ and a negative response to both of these questions.

\section{QUICK LOOK}

\section{Current knowledge}

Patients with undiagnosed COPD require diagnosis for early treatment. Unfortunately, underdiagnosis is common. Previous studies have explored the characteristics of individuals with undiagnosed COPD, but they have not always been based on post-bronchodilator spirometry despite guidelines that state COPD diagnosis should always be based on post-bronchodilator spirometry.

\section{What this paper contributes to our knowledge}

We explored potential characteristics of subjects with undiagnosed COPD based on post-bronchodilator spirometry. Subjects with undiagnosed COPD were characterized by better health status than subjects with a COPD diagnosis. The undiagnosed subjects had fewer symptoms, better lung function, and were less limited in their daily life than their diagnosed counterparts.

\section{Identification of Potential Characteristics}

Potential characteristics of subjects with undiagnosed COPD were identified by consulting existing literature about characteristics of COPD and undiagnosed COPD. ${ }^{8,9,12-17}$ Whenever a potential characteristic was identified, it was noted. Based on this analysis, all available variables in the NHANES dataset (2007-2012) were scrutinized to match one or more variables to each potential characteristic identified in the literature. Additional variables from the NHANES dataset that were considered relevant by the authors were added to the list of potential characteristics presented in Table 2.

\section{Statistical Analysis}

MATLAB Release 2015b (MathWorks, Natick, Massachusetts) was used for merging and processing the data. The statistical analyses were performed using SPSS 23 (IBM, SPSS Statistics, Armonk, New York). Nominal variables were tested using Pearson's chi-squared test. Ordinal variables were tested using the Mann-Whitney U test. Continuous variables were tested for normality through visual inspection of histograms and QQ-plots, and for homogeneity of variance using Levene's test. Continuous variables lacking either normality or homogeneity of variances were tested using the Mann-Whitney U test. Continuous variables that were normally distributed and showing homogeneity of variance were tested using the $t$ test. To correct for the accumulated type- 1 error, Bonferroni cor- 


\section{Characteristics of Subjects With Undiagnosed COPD}

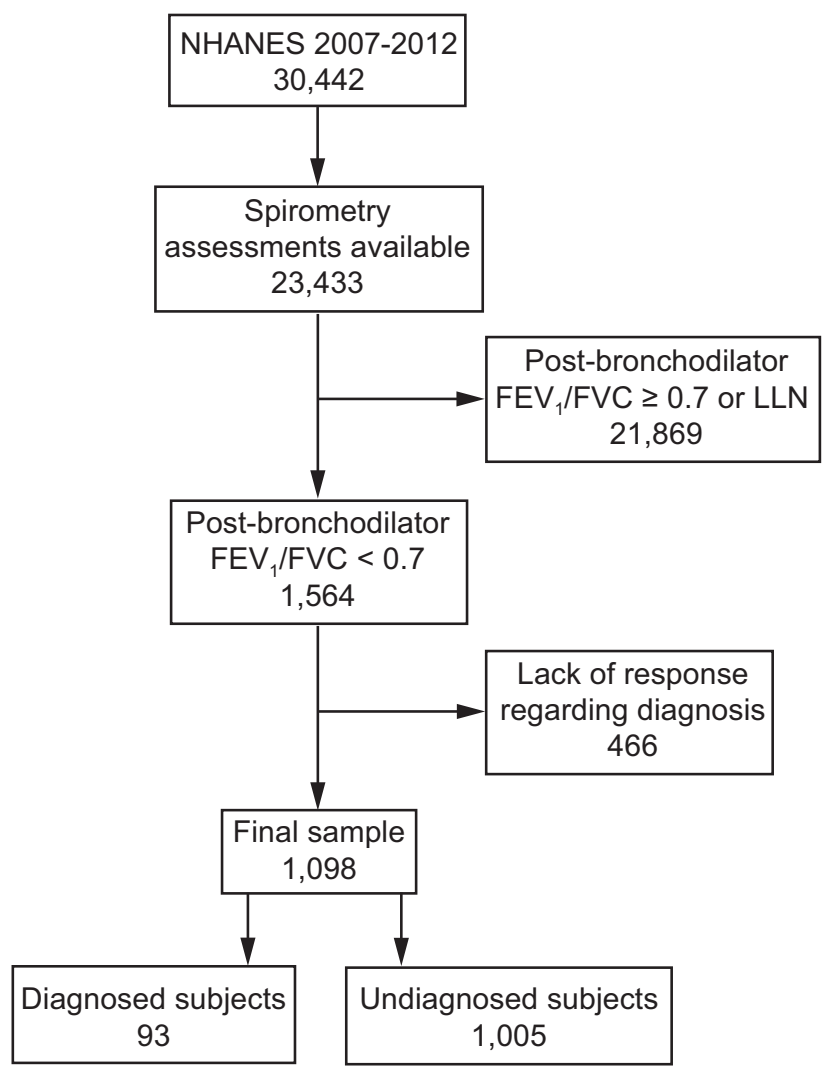

Fig. 1. Flow chart. NHANES $=$ National Health and Nutrition Examination Survey; LLN = lower limit of normal.

Table 1. Baseline characteristics

\begin{tabular}{lc}
\hline \hline Age, y, median (IQR) & $53(28)$ \\
Male gender, $\%$ & 64.6 \\
Body mass index, $\mathrm{kg} / \mathrm{m}^{2}$, mean $(\mathrm{SD})$ & $27.47(5.69)$ \\
Current smoker, $\%$ & 35.5 \\
Pre-bronchodilator $\mathrm{FEV}_{1} / \mathrm{FVC}$, mean (SD) & $0.66(0.06)$ \\
Post-bronchodilator $\mathrm{FEV}_{1} / \mathrm{FVC}$, mean (SD) & $0.70(0.08)$ \\
& \\
$N=1,098$ subjects. & \\
$\mathrm{IQR}=$ interquartile range \\
Current smoker $=$ smokes every day or some days
\end{tabular}

rection was applied, and each hypothesis was tested against a 2-tailed significance level of $P<.001(P<.05 / 51)$.

\section{Results}

A total of 13 out of 51 factors were significant in characterizing subjects with undiagnosed COPD (Table 2). Undiagnosed subjects had fewer respiratory symptoms, including phlegm $(P<.001)$, wheezing $(P<.001)$, and chest pain $(P<.001)$ than subjects with diagnosed COPD. The subjects with undiagnosed COPD were also characterized by less shortness of breath on stairs/inclines $(P<.001)$, fewer work/school days lost to wheezing $(P<.001)$, less sleep disturbance due to wheezing $(P<.001)$, and less difficulty socializing $(P<.001)$ than subjects with diagnosed COPD. Moreover, the subjects with undiagnosed COPD felt less depressed $(P<.001)$ than the subjects with diagnosed COPD $(P<.001)$.

The subjects with undiagnosed COPD were less likely to ever have had asthma $(P<.001)$ and to currently have asthma $(P<.001)$. Furthermore, the annual household income was higher among the undiagnosed subjects $(P<.001)$ than among their diagnosed counterparts. Finally, the undiagnosed subjects were characterized by a higher pre-bronchodilator $\mathrm{FEV}_{1}(P<.001)$ and FVC $(P<.001)$.

\section{Discussion}

This study aimed to explore the characteristics of subjects with undiagnosed COPD from the NHANES dataset (2007-2012). The statistical analysis showed a multitude of factors that characterize the subjects. Overall, their health status was superior to that of diagnosed subjects given that they had fewer symptoms and were less limited in their daily lives. The undiagnosed subjects also had better lung function as exhibited by higher $\mathrm{FEV}_{1}$ and FVC.

A study by Martinez et $\mathrm{al}^{8}$ explored the characteristics of undiagnosed COPD based on the NHANES dataset. However, their analysis was based on pre-bronchodilator spirometry, and COPD should be confirmed based only on post-bronchodilator spirometry. ${ }^{2}$ In our study, we therefore focused on subjects in whom post-bronchodilator spirometry had been performed and who had a post-bronchodilator $\mathrm{FEV}_{1} / \mathrm{FVC}<0.7$. The study by Martinez et $\mathrm{al}^{8}$ identified the following characteristics of subjects with undiagnosed COPD from the NHANES dataset 2007-2012: female sex, higher age, lower body mass index (BMI), fewer respiratory symptoms, and higher $\mathrm{FEV}_{1}$. These results partly mirror our findings where fewer respiratory symptoms, and a higher $\mathrm{FEV}_{1}$ characterized subjects with undiagnosed COPD. However, in our study neither higher age, female sex, nor lower BMI was statistically significantly associated with undiagnosed COPD.

The results of our study are comparable to those of a Norwegian study, which also found that undiagnosed subjects with COPD were characterized by better lung function and fewer respiratory symptoms than diagnosed subjects. Similar results were also found in an international study by Lamprecht et al ${ }^{12}$ in which undiagnosed COPD was related to less severe air-flow limitation. However, the results from Lamprecht et al differs from our findings because they found, among other things, that undiagnosed subjects were more likely to be male, younger, and have lower education. ${ }^{12}$ The findings of our study also mirror those of a Brazilian study, which found an association 


\section{Characteristics of Subjects With Undiagnosed COPD}

Table 2. Characteristics of Subjects With Undiagnosed COPD

\begin{tabular}{|c|c|c|c|}
\hline Characteristic & Undiagnosed & Diagnosed & $P$ \\
\hline \multicolumn{4}{|l|}{ Nominal variables, $\mathrm{n} / \mathrm{N}(\%)$} \\
\hline Currently have asthma & $106 / 1,005(10.6)$ & $26 / 93(28.0)$ & $<.001$ \\
\hline Ever had pain or discomfort in chest $(\mathrm{Y} / \mathrm{N})$ & $157 / 697(22.5)$ & $32 / 74(43.4)$ & $<.001$ \\
\hline Had a head cold or chest cold within $30 \mathrm{~d}(\mathrm{Y} / \mathrm{N})$ & $172 / 948(18.1)$ & $12 / 86(13.9)$ & .21 \\
\hline Ever been told you had coronary heart disease $(\mathrm{Y} / \mathrm{N})$ & $33 / 999(3.3)$ & $5 / 92(5.4)$ & .21 \\
\hline Coughing most days over a 3-month period $(\mathrm{Y} / \mathrm{N})$ & $93 / 698(13.3)$ & $20 / 74(27.0)$ & .003 \\
\hline Ever been told by a doctor that you have diabetes $(\mathrm{Y} / \mathrm{N})$ & 95/993 (9.6) & $14 / 90(15.6)$ & .06 \\
\hline Problem taking a deep breath (dyspnea) $(\mathrm{Y} / \mathrm{N})$ & $0 / 1,005(0)$ & $0 / 93(0)$ & No data \\
\hline Ever been told that you have asthma $(\mathrm{Y} / \mathrm{N})$ & 195/1,003 (19.4) & $41 / 93(44.1)$ & $<.001$ \\
\hline Smoked at least 100 cigarettes in life $(\mathrm{Y} / \mathrm{N})$ & $632 / 1,005(62.9)$ & $72 / 93(77.4)$ & .003 \\
\hline Ever exposed to exhaust fumes at work $(\mathrm{Y} / \mathrm{N})$ & 300/992 (30.2) & $39 / 92(42.4)$ & .01 \\
\hline Ever had work exposure to mineral dusts $(\mathrm{Y} / \mathrm{N})$ & $394 / 989(39.8)$ & $42 / 91(46.2)$ & .14 \\
\hline Ever had work exposure to organic dusts (Y/N) & 268/991 (27.0) & 25/92 (27.2) & .53 \\
\hline Ever had work exposure to other fumes (Y/N) & $379 / 992(38.2)$ & $39 / 92(49.4)$ & .25 \\
\hline Close relative had asthma $(\mathrm{Y} / \mathrm{N})$ & 196/990 (19.8) & $17 / 90(18.9)$ & .48 \\
\hline Male gender & $655 / 1,005(65.2)$ & $54 / 93(58.1)$ & .11 \\
\hline Episode of hay fever in past 12 months $(\mathrm{Y} / \mathrm{N})$ & $182 / 998(18.2)$ & $17 / 93(18.3)$ & .54 \\
\hline Ever told that you had congestive heart failure $(\mathrm{Y} / \mathrm{N})$ & $15 / 1,000(1.5)$ & $4 / 93(4.3)$ & .07 \\
\hline Ever told that you had high blood pressure (Y/N) & $307 / 1,004(30.6)$ & $37 / 93(39.8)$ & .05 \\
\hline Ever told that you had lung cancer/malignancy & $2 / 1,005(0.2)$ & $0 / 93(0)$ & .84 \\
\hline Marital status $\dagger$ & & & .83 \\
\hline Married & $565 / 1,005(56.2)$ & $50 / 93(53.8)$ & \\
\hline Widowed & $44 / 1,005(4.4)$ & $4 / 93(4.3)$ & \\
\hline Divorced & $126 / 1,005(12.5)$ & $13 / 93(14.0)$ & \\
\hline Separated & $22 / 1,005(2.2)$ & $4 / 93(4.3)$ & \\
\hline Never married & $149 / 1,005(14.8)$ & $12 / 93(12.9)$ & \\
\hline Living with partner & $99 / 1,005(9.9)$ & $10 / 93(10.8)$ & \\
\hline Bring up phlegm most days in a 3-month period $(\mathrm{Y} / \mathrm{N})$ & 77/698 (11.0) & $24 / 74(32.4)$ & $<.001$ \\
\hline Race & & & .42 \\
\hline Mexican-American & $108 / 1,005(10.8)$ & $5 / 93(5.4)$ & \\
\hline Other Hispanic & $70 / 1,005(7.0)$ & $5 / 93(5.4)$ & \\
\hline Non-Hispanic white & $578 / 1,005(57.5)$ & $61 / 93(65.6)$ & \\
\hline Non-Hispanic black & $182 / 1,005(18.1)$ & $15 / 93(16.1)$ & \\
\hline Other & $67 / 1,005(6.7)$ & $7 / 93(7.5)$ & \\
\hline Moderate recreational activities $(\mathrm{Y} / \mathrm{N})$ & $431 / 1,005(42.9)$ & $39 / 93(41.9)$ & .48 \\
\hline Had respiratory illness in the past $7 \mathrm{~d}(\mathrm{Y} / \mathrm{N})$ & 236/978 (24.1) & 28/91 (30.8) & .10 \\
\hline Shortness of breath on stairs/inclines $(\mathrm{Y} / \mathrm{N})$ & $197 / 1,005(19.6)$ & $53 / 93(57.0)$ & $<.001$ \\
\hline Does anyone smoke inside home $(\mathrm{Y} / \mathrm{N})$ & $259 / 1,005(25.8)$ & $32 / 93(34.4)$ & .05 \\
\hline Ever told doctor that you had trouble sleeping $(\mathrm{Y} / \mathrm{N})$ & $223 / 1,005(22.2)$ & $27 / 93(29.0)$ & .09 \\
\hline Vigorous work activity $(\mathrm{Y} / \mathrm{N}) \dagger$ & $258 / 1,005(25.7)$ & $22 / 93(23.7)$ & .39 \\
\hline Wheezing or whistling in chest in the past year $(\mathrm{Y} / \mathrm{N})$ & $194 / 1,005(19.3)$ & $51 / 93(54.8)$ & $<.001$ \\
\hline \multicolumn{4}{|l|}{ Ordinal variables } \\
\hline Work/school days lost due to wheezing (0-3) & & & $<.001$ \\
\hline None & $982 / 1,005(97.7)$ & $83 / 93(89.3)$ & \\
\hline $1-7 \mathrm{~d}$ & $120 / 1,005(2.0)$ & $6 / 93(6.5)$ & \\
\hline $8-30 \mathrm{~d}$ & $2 / 1,005(0.2)$ & $2 / 93(2.2)$ & \\
\hline$\geq 31 \mathrm{~d}$ & $1 / 1,005(0.1)$ & $2 / 93(2.2)$ & \\
\hline Feeling down, depressed, or hopeless (0-3) & & & $<.001$ \\
\hline Not at all & $826 / 1,005(82.2)$ & $63 / 93(67.7)$ & \\
\hline Several days & $140 / 1,005(13.9)$ & $20 / 93(21.5)$ & \\
\hline More than half of the days & $23 / 1,005(2.3)$ & $6 / 93(6.5)$ & \\
\hline Nearly every day & $16 / 1,005(1.6)$ & $4 / 93(4.3)$ & \\
\hline
\end{tabular}




\section{Characteristics of Subjects With Undiagnosed COPD}

Table 2. Continued

\begin{tabular}{|c|c|c|c|}
\hline Characteristic & Undiagnosed & Diagnosed & $P$ \\
\hline Difficulty walking a quarter mile & & & .18 \\
\hline Not at all & $926 / 1,005(92.1)$ & $82 / 93(88.2)$ & \\
\hline Several days & $55 / 1,005(5.5)$ & $7 / 93(7.5)$ & \\
\hline More than half of the days & $16 / 1,005(1.6)$ & $2 / 93(2.2)$ & \\
\hline Nearly every day & $5 / 1,005(0.5)$ & $2 / 93(2.2)$ & \\
\hline Do not do this & $3 / 1,005(0.3)$ & $0 / 93(0)$ & \\
\hline Difficulty walking up 10 steps & & & .001 \\
\hline No difficulty & $957 / 1,005(95.2)$ & $81 / 93(87.1)$ & \\
\hline Some difficulty & $39 / 1,005(3.9)$ & $9 / 93(9.7)$ & \\
\hline Much difficulty & $5 / 1,005(0.5)$ & $2 / 93(2.2)$ & \\
\hline Unable to do this & $1 / 1,005(0.01)$ & $1 / 93(1.1)$ & \\
\hline Do not do this & $3 / 1,005(0.3)$ & $0 / 93(0)$ & \\
\hline Education level of adults $>20 \mathrm{y}$ old & & & .46 \\
\hline Less than ninth grade & $90 / 1,005(7.0)$ & 4/93 (4.3) & \\
\hline Ninth to eleventh grade & $167 / 1,005(16.6)$ & 19/93 (20.4) & \\
\hline High school & $233 / 1,005(23.9)$ & $30 / 93(32.3)$ & \\
\hline Some college & $285 / 1,005(28.4)$ & $22 / 93(23.7)$ & \\
\hline College graduate & $230 / 1,005(22.9)$ & 18/93 (19.4) & \\
\hline Fatigue: feeling tired or having little energy & & & .003 \\
\hline Not at all & $602 / 1,005(59.9)$ & $42 / 93(45.2)$ & \\
\hline Several days & $293 / 1,005(29.2)$ & $32 / 93(34.4)$ & \\
\hline More than half of the days & $46 / 1,005(4.9)$ & $12 / 93(12.9)$ & \\
\hline Nearly every day & $64 / 1,005(6.4)$ & $7 / 93(7.5)$ & \\
\hline General health & & & .007 \\
\hline Excellent & $86 / 952(9.0)$ & $4 / 86(4.7)$ & \\
\hline Very good & $314 / 952(33.0)$ & $24 / 86(27.9)$ & \\
\hline Good & $385 / 952(40.4)$ & $32 / 86(37.2)$ & \\
\hline Fair & $151 / 952(15.9)$ & $21 / 86(24.4)$ & \\
\hline Poor & $16 / 952(1.7)$ & $5 / 86(5.8)$ & \\
\hline Annual household income & & & $<.001$ \\
\hline$\$ 0-4,999$ & $23 / 931(2.5)$ & $7 / 86(8.1)$ & \\
\hline$\$ 5,000-9,999$ & 35/931 (3.8) & $4 / 86(4.7)$ & \\
\hline$\$ 10,000-14,999$ & 72/931 (7.7) & $12 / 86(14.0)$ & \\
\hline$\$ 15,000-19,999$ & $58 / 931(6.2)$ & $9 / 86(10.5)$ & \\
\hline$\$ 20,000-24,999$ & 82/931 (8.8) & $5 / 86(5.8)$ & \\
\hline$\$ 25,000-34,999$ & $107 / 931(11.5)$ & $15 / 86(17.4)$ & \\
\hline$\$ 35,000-44,999$ & 96/931 (10.3) & $7 / 86(8.1)$ & \\
\hline$\$ 45,000-54,999$ & $82 / 931(8.8)$ & $5 / 86(5.8)$ & \\
\hline$\$ 55,000-64,999$ & $59 / 931(6.3)$ & $4 / 86(4.7)$ & \\
\hline$\$ 65,000-74,999$ & $50 / 931(5.4)$ & $5 / 86(5.8)$ & \\
\hline$\$ 75,000-99,999$ & $112 / 931(12.0)$ & $9 / 86(10.5)$ & \\
\hline$\$ 100,000$ and over & $155 / 931(16.7)$ & $4 / 86(4.7)$ & \\
\hline Do you now smoke cigarettes $(\mathrm{Y} / \mathrm{N})$ & & & .06 \\
\hline Every day & $318 / 1,005(31.6)$ & $36 / 93(38.7)$ & \\
\hline Some days & $30 / 1,005(3.0)$ & $6 / 93(6.5)$ & \\
\hline Not at all & $656 / 1,005(65.3)$ & $51 / 93(54.8)$ & \\
\hline Difficulty attending social events & & & $<.001$ \\
\hline No difficulty & $957 / 1,005(95.2)$ & $79 / 93(85.0)$ & \\
\hline Some difficulty & $24 / 1,005(2.4)$ & $11 / 93(11.8)$ & \\
\hline Much difficulty & $8 / 1,005(0.8)$ & $1 / 93(1.1)$ & \\
\hline Unable to attend & $6 / 1,005(0.6)$ & $0 / 93(0)$ & \\
\hline Do not do this & $10 / 1,005(1.0)$ & $2 / 93(2.2)$ & \\
\hline
\end{tabular}




\section{Characteristics of Subjects With Undiagnosed COPD}

Table 2. Continued

\begin{tabular}{|c|c|c|c|}
\hline Characteristic & Undiagnosed & Diagnosed & $P$ \\
\hline Wheezing disturbed sleep in past year & & & $<.001$ \\
\hline Never & $914 / 1,005(91.0)$ & $66 / 93(71)$ & \\
\hline$<1$ night/week & $39 / 1,005(3.9)$ & $13 / 93(14)$ & \\
\hline$\geq 1$ night/week & $52 / 1,005(5.2)$ & $14 / 93(15.1)$ & \\
\hline \multicolumn{4}{|c|}{$\begin{array}{l}\text { Continuous variables lacking normality/homogeneity of } \\
\text { variances, median (IQR) }\end{array}$} \\
\hline Age at screening, y & $52(28)$ & $57(20)$ & .01 \\
\hline Anxiety in the past $30 \mathrm{~d}, \mathrm{~d} \dagger$ & $0(5)$ & $0(7.8)$ & .47 \\
\hline Body mass index, $\mathrm{kg} / \mathrm{m}^{2}$ & $26.50(6.8)$ & $27.03(8.4)$ & .31 \\
\hline Cigarettes smoked in household, no. & $0(0)$ & $0(6.3)$ & .09 \\
\hline Days with moderate recreational activity, $\mathrm{d}$ & $0(3)$ & $0(3)$ & .87 \\
\hline Days with vigorous work, $\mathrm{d}$ & $0(1)$ & $0(0)$ & .48 \\
\hline Time smoking, pack-years & $8.41(23.8)$ & $18.87(29.7)$ & .001 \\
\hline \multicolumn{4}{|l|}{$\begin{array}{c}\text { Continuous variables normally distributed and with } \\
\text { homogeneity of variance, mean }(\%)\end{array}$} \\
\hline Pre-bronchodilator $\mathrm{FEV}_{1}$ & $2.82(0.8)$ & $2.34(0.9)$ & $<.001$ \\
\hline Pre-bronchodilator FVC & $4.25(1.1)$ & $3.68(1.3)$ & $<.001$ \\
\hline Pre-bronchodilator $\mathrm{FEV}_{1} / \mathrm{FVC}$ & $0.66(0.1)$ & $0.63(0.1)$ & .001 \\
\hline Waist circumference, $\mathrm{cm} \dagger$ & $97.07(14.7)$ & $100.02(16.5)$ & .10 \\
\hline
\end{tabular}

between undiagnosed COPD and less wheezing and less severe disease. ${ }^{9}$ Thus there seems to be general agreement between these studies and ours, subjects with undiagnosed COPD have better lung function and fewer symptoms than those diagnosed with the disease. However, the significance of other characteristics such as age, income, and educational level still needs to be determined.

Based on the results of this study, we are unable to explain why the subjects remained undiagnosed even though they had a post-bronchodilator $\mathrm{FEV}_{1} / \mathrm{FVC}<0.7$. Our data does not reveal whether the undiagnosed subjects failed to see a doctor or if the doctor failed to diagnose the subjects. Fromer et al ${ }^{19}$ found that lack of knowledge and awareness of COPD may cause health care professionals to delay COPD diagnosis until the severity of the disease has progressed. COPD may be challenging to diagnose at an early stage due to milder symptoms. This mirrors the findings of Akamatsu et al, ${ }^{20}$ who found that approximately half of their subjects with COPD never had any respiratory symptoms. Thus, patients with mild symptoms may be less inclined to see a doctor. In addition, one may assume that it is difficult for the doctor to determine a COPD diagnosis if the patient does not complain about respiratory symptoms. The rate of undiagnosed subjects in our study is very high: of 1,098 subjects with a post-bronchodilator $\mathrm{FEV}_{1} / \mathrm{FVC}<0.7,1,005$ subjects $(91.53 \%)$ reported no previous diagnosis. This may be explained by the study definition of undiagnosed COPD. The subjects were asked if their doctor had ever told them that they had chronic bron- chitis or emphysema. There is a risk that some subjects may not have understood the question and consequently responded negatively to the question despite a previous diagnosis. However, the fact that the undiagnosed subjects had fewer respiratory symptoms may also explain the high rate of undiagnosed subjects.

Spirometry criteria are also an important factor in COPD diagnosis. ${ }^{21}$ GOLD argues that the threshold of post-bronchodilator $\mathrm{FEV}_{1} / \mathrm{FVC}<0.7$ should remain, ${ }^{22}$ whereas multiple studies argue that LLN should be used as an alternative threshold for defining COPD. ${ }^{23-27}$ Woodruff et $\mathrm{al}^{28}$ found that current or former smokers who did not meet the existing criteria for COPD had evidence of airway disease. Current or former smokers in their study had exacerbations, were limited in their activities, and were commonly treated with respiratory medication. These findings suggest that spirometry alone may not be sufficient to diagnose COPD correctly. ${ }^{28}$ Similarly, Brusasco et $\mathrm{al}^{29}$ concluded that spirometry should not be the only pulmonary function test in COPD. Further investigation of alternative pulmonary function tests is recommended to avoid misclassification of COPD.

Overdiagnosis also represents a challenge in COPD. A recent study by Spero et $\mathrm{al}^{30}$ found that approximately one third of hospitalized subjects with a COPD diagnosis might not have COPD. Several factors were associated with overdiagnosis, including various comorbidities, high BMI, and less smoking. ${ }^{30}$ These findings are in line with other studies that have explored the rate of COPD overdiagnosis, 


\section{Characteristics of Subjects With Undiagnosed COPD}

with a rate ranging from $27.2-51.6 \% .{ }^{31}$ Future research may explore the characteristics of overdiagnosed patients to optimize COPD diagnosis.

A report by the U.S. Preventive Services Task Force concluded that no direct evidence supports that screening patients for COPD using spirometry will improve their health outcomes in the long term. ${ }^{32}$ This conclusion echoes the most recent recommendations by GOLD, which state that no evidence supports the introduction of screening spirometry to inform management decisions or improve outcomes in subjects without significant symptoms. However, GOLD does recommend active COPD case finding. ${ }^{3}$ A study based on data from the Burden of Obstructive Lung Disease Study (BOLD) suggests that focused case findings based on a simple peak-flow assessment will improve COPD case finding as opposed to using a screening questionnaire. ${ }^{33}$ Another study by Jordan et $\mathrm{al}^{34}$ found that a case finding approach including questionnaires would identify significantly more new cases of COPD. ${ }^{34} \mathrm{We}$ may safely assume that strategies for COPD case finding still require further development and testing. Our study adds input to that development, and we assume that a focused algorithm based on known characteristics of undiagnosed patients with COPD may improve COPD case finding.

This study has some limitations. One is the fact that the included subjects were not asked directly if they had a COPD diagnosis. Instead, we presumed the presence of a diagnosis if the subjects responded affirmatively when asked if they had been told that they had chronic bronchitis or emphysema. Some subjects with a COPD diagnosis may therefore have been wrongfully defined as undiagnosed, and vice versa. However, the procedure of defining diagnosed COPD as a positive response to having chronic bronchitis/emphysema was used in similar studies, ${ }^{8,35}$ and it is considered the best available solution when using the NHANES dataset. Another limitation is that the presumed COPD diagnosis is based solely on spirometry, as a COPD diagnosis should ideally rest on a more holistic assessment. ${ }^{2}$ However, spirometry is the key to COPD diagnosis, ${ }^{2}$ which justifies the use of a spirometry-based definition of COPD. This study was limited by the fact that not all potential characteristics of subjects with undiagnosed COPD were available in the NHANES data set, so history of lower respiratory tract infection, peripheral artery disease, peptic ulcer, and edema were not considered. Future studies may find it relevant to look into these characteristics as well. Finally, our sample may not be representative across all COPD severity grades as one may assume that the more severe cases are less likely to participate in a survey such as the NHANES. Thus, precaution is required when applying the present results to all COPD severity grades.

\section{Conclusions}

In conclusion, we found that subjects with undiagnosed COPD were characterized by a better health status than subjects with diagnosed COPD. The undiagnosed subjects had fewer symptoms, better lung function, and were less limited in their daily life than subjects who had been diagnosed with COPD. Future research should focus on improving COPD case finding focusing on known characteristics of undiagnosed patients with COPD.

\section{REFERENCES}

1. European Respiratory Society. European Lung White Book 2014. https://www.erswhitebook.org. Accessed May 142018.

2. Roisin RR. Chronic Obstructive Pulmonary Disease Updated 2010. Global Initiative for Chronic Obstructive Lung Disease. 2016;1-94.

3. López-Campos JL, Tan W, Soriano JB. Global burden of COPD. Respirology 2016;21(1):14-23.

4. Qaseem A, Wilt T, Weinberger S, Hanania N, Criner G, Van der Molen $\mathrm{T}$, et al. Diagnosis and management of stable chronic obstructive pulmonary disease: a clinical practice guideline update from the American College of Physicians, American College of Chest Physicians, American Thoracic Society and European Respiratory Society. Ann Intern Med 2011;(155):179-191.

5. Soriano JB, Zielinski J, Price D. Screening for and early detection of chronic obstructive pulmonary disease. Lancet 2009;374(9691):721732

6. Miller MR, Levy ML. Chronic obstructive pulmonary disease: missed diagnosis versus misdiagnosis. BMJ 2015;351:h3021.

7. Mapel DW, Robinson SB, Dastani HB, Shah H, Phillips AL, Lydick E. The direct medical costs of undiagnosed chronic obstructive pulmonary disease. Value Heal 2008;11(4):628-636.

8. Martinez CH, Mannino DM, Jaimes FA, Curtis JL, Han MLK, Hansel NN, et al. Undiagnosed obstructive lung disease in the United States associated factors and long-term mortality. Ann Am Thorac Soc 2015;12(12):1788-1795.

9. Santos SR, Lizzi ES, Vianna EO. Characteristics of undiagnosed COPD in a senior community center. Int J COPD 2014;9:1155-1161.

10. National Centers for Health Statistics. National Health and Nutrition Examination Survey. https://www.cdc.gov/nchs/nhanes/index.htm. Accessed May 14, 2018.

11. Zipf G, Chiappa M, Porter KS, Ostchega Y, Lewis BG, Dostal J. National health and nutrition examination survey: plan and operations, 1999-2010. Vital Health Stat 1 2013;(56):1-37.

12. Lamprecht B, Soriano JB, Studnicka M, Kaiser B. Determinants of underdiagnosis of COPD in national and international surveys. Chest 2015;148(4):971-985.

13. Mapel DW, Frost FJ, Hurley JS, Petersen H, Roberts M, Marton JP, et al. An algorithm for the identification of undiagnosed COPD cases using administrative claims data. J Manag Care Pharm 2006;12(6): 457-465.

14. Balcells E, Gimeno-Santos E, de Batlle J, Ramon MA, Rodríguez E, Benet $\mathrm{M}$, et al. Characterisation and prognosis of undiagnosed chronic obstructive pulmonary disease patients at their first hospitalisation. BMC Pulm Med 2015;15(1):1-9.

15. Marceau K, Ruttle PL, Shirtcliff EA, Essex MJ, Susman EJ, Studies A, et al. Identifying patients with undiagnosed COPD in primary care settings: insight from screening tools and epidemiologic studies. Chronic Obs Pulm Dis 2015;57(6):742-768.

16. Koblizek V, Novotna B, Zbozinkova Z, Hejduk K. Diagnosing COPD: advances in training and practice - a systematic review. Adv Med Educ Pract 2016;7:219-231. 


\section{Characteristics of Subjects With Undiagnosed COPD}

17. Gershon AS, Hwee J, Chapman KR, Aaron SD, O'Donnell DE, Stanbrook MB, et al. Factors associated with undiagnosed and overdiagnosed COPD. Eur Respir J 2016;48(2):561-564.

18. Hvidsten SC, Storesund L, Wentzel-Larsen T, Gulsvik A, Lehmann $\mathrm{S}$. Prevalence and predictors of undiagnosed chronic obstructive pulmonary disease in a Norwegian adult general population. Clin Respir J 2010;4(1):13-21.

19. Fromer L. Diagnosing and treating COPD: understanding the challenges and finding solutions. Int J Gen Med 2011;4:729-739.

20. Akamatsu K, Yamagata T, Kida Y, Tanaka H, Ueda H, Ichinose M. Poor sensitivity of symptoms in early detection of COPD. COPD 2008;5(5):269-273.

21. Hangaard S, Helle T, Nielsen C, Hejles. Causes of misdiagnosis of chronic obstructive pulmonary disease: a systematic scoping review. Respir Med 2017;129:63-84.

22. GOLD. Global Initiative for Chronic Obstructive. http://www.goldcopd. org. Accessed May 14, 2018.

23. Aggarwal AN, Gupta D, Agarwal R, Jindal SK. Comparison of the lower confidence limit to the fixed-percentage method for assessing airway obstruction in routine clinical practice. Respir Care 2011; 56(11):1778-1784.

24. Cerveri I, Corsico a G, Accordini S, Niniano R, Ansaldo E, Antó JM, et al. Underestimation of airflow obstruction among young adults using FEV1/FVC $<70 \%$ as a fixed cut-off: a longitudinal evaluation of clinical and functional outcomes. Thorax 2008;63(12):1040-1045.

25. Lamprecht B, Schirnhofer L, Kaiser B, Buist S a, Mannino DM, Studnicka M. Subjects with Discordant airways obstruction: lost between spirometric definitions of COPD. Pulm Med 2011;780215.

26. Miller MR, Quanjer PH, Swanney MP, Ruppel G, Enright PL. Interpreting lung function data using $80 \%$ predicted and fixed thresholds misclassifies more than $20 \%$ of patients. Chest 2011; 139(1):52-59.

27. Schermer TRJ, Smeele IJM, Thoonen BP, Lucas EM, Grootens JG, van Boxem TJ, et al. Current clinical guideline definitions of airflow obstruction and COPD overdiagnosis in primary care. Eur Respir J 2008;32(4):945-952.

28. Woodruff PG, Barr RG, Bleecker E, Christenson SA, Couper D, Curtis JL, et al. Clinical significance of symptoms in smokers with preserved pulmonary function. N Engl J Med 2016;374(19):18111821.

29. Brusasco V, Barisione G, Crimi E. Pulmonary physiology: future directions for lung function testing in COPD VITO. Respirology 2015;20:209-218

30. Spero K, Bayasi G, Beaudry L, Barber KR, Khorfan F. Overdiagnosis of COPD in hospitalized patients. Int J COPD 2017;12:24172423.

31. Ghattas C, Dai A, Gemmel DJ, Awad MH. Over diagnosis of chronic obstructive pulmonary disease in an underserved patient population. Int J Chron Obstruct Pulmon Dis 2013;8:545-549.

32. U.S. Preventive Services Task Force. Screening for chronic obstructive pulmonary disease using spirometry: U.S. Preventive Services Task Force recommendation statement (archived). March 2008. https://www.uspreventiveservicestaskforce.org/Page/Document/ UpdateSummaryFinal/chronic-obstructive-pulmonary-disease-copdscreening. Accessed June 29, 2018

33. Jithoo A, Enright PL, Burney P, Buist AS, Bateman ED, Tan WC, et al. Case-finding options for COPD: results from the burden of obstructive lung disease study. Eur Respir J 2013;41(3):548-555.

34. Jordan RE, Lam KH, Cheng KK, Miller MR, Marsh JL, Ayres JG, et al. Case finding for chronic obstructive pulmonary disease: a model for optimising a targeted approach. Thorax 2010;65(6):492498.

35. Schnell K, Weiss CO, Lee T, Krishnan JA, Leff B, Wolff JL, et al. The prevalence of clinically-relevant comorbid conditions in patients with physician-diagnosed COPD: a cross-sectional study using data from NHANES 1999-2008. BMC Pulm Med 2012; 12(1):26. 